\title{
Oral Manifestations in the Cornelia De Lange Syndrome: A Systematic Review of the Dental Literature.
}

\author{
José González-Serrano ${ }^{1}$, Víctor Manuel Paredes-Rodríguez ${ }^{1}$, \\ Carlos González-Serrano ${ }^{2}$, Gema Torrijos Gómez ${ }^{3}$, Jorge A. Cano-Durán ${ }^{1}$, \\ Juan Francisco Peña-Cardelles ${ }^{1}$, Daniel Ortega-Concepción ${ }^{1}$. \\ ${ }^{1}$ Department of Oral Medicine and Orofacial Surgery. Faculty of Odontology. Complutense University. \\ Madrid, Spain. \\ ${ }^{2}$ Rey Juan Carlos University, Alcorcón, Madrid. Spain. \\ ${ }^{3}$ Faculty of Odontology. Complutense University. Madrid, Spain.
}

\begin{abstract}
The Cornelia de Lange syndrome (CdLS) is a genetic disorder that affects newborns between 1/10.000 and 1:100.000, and whose diagnosis is established based on medical history and clinical examination, characterized by growth retardation and development, hirsutism, structural abnormalities in the limbs and distinctive facial features. The aim of this paper is to provide a systematic review of the literature on oral manifestations of this rare disease, describing 7 published cases of CdLS in the indexed literature (PubMed/MEDLINE) - the first corresponds to the year 1980 and the last in 2009. Dental problems among these patients are common and include: delayed eruption, malocclusion, micrognathia, dental malpositions, extensive caries or periodontal disease. In any case, the delayed eruption, which may be the cause of diastemas and / or malocclusion is the most common oral finding associated with CdLS - which early diagnosis is key.
\end{abstract}

Keywords: Cornelia de Lange syndrome, oral manifestations, systematic review.

\section{Introduction}

The Cornelia de Lange syndrome (CdLS) is a rare developmental malformation characterized by a learning disability by a variable degree of intellectual impairment, short stature due to their growth retardation, abnormalities in the limbs (oligodactyly, amputations...) and a particular facial dysmorphism [1]. They may also have other malformations in organs such as the heart or kidney [2]. It was first described by Dr. Cornelia de Lange, who published two cases of children with similar traits [3]. The syndrome has also been called Brachmann de Lange, as was Dr. Brachmann in 1916 who described similar symptoms in one patient [4]. The estimated incidence varies from $1 / 10.000$ to $1 / 100.000$ live births [5]. Virtually all cases are sporadic but may occur following an autosomal dominant pattern [6]. The NIPBL gene, one of the 3 known involved, is mutated in 50\% of cases [7]. However, the diagnosis continues to be established with the clinical history and examination. Distinctive facial findings are widely accepted as diagnostic criteria of CdLS (Table 1) [8]: curved eyebrows, confluent and well-defined, long and curly eyelashes, anteverted nostrils and mouth downturned with a thin upper lip, giving it the aspect of crescent shaped mouth. However, cases have been described with atypical facial features that can cause uncertain diagnosis [9]. There is no specific treatment for CdLS but therapies aimed at improving behavior, stimulation and neurodevelopmental program along with a number of drugs to control seizures that these patients can undergo [10].

Oral manifestations of CdLS have been briefly described in the medical literature. As for the dental literature, there are some articles describing the oral pathology of these patients. The present study aims to provide a systematic review of the literature on oral manifestations of this rare disease.

\section{Material And Methods}

A literature search on the subject in question on the basis of PubMed/MEDLINE data up to May 10th, 2016 was performed the following keywords were used: Cornelia de Lange syndrome AND OR dental oral manifestation. The articles were independently assessed by two reviewers (JGS, VMPR). The inclusion criteria were: articles in English generated by the MEDLINE database, submit (at least) a case with oral manifestations and to describe oral characteristics of the disorder and the treatment used in this case. Of the 58 articles found, only six met the requirements. 


\section{Results}

The first article published in the dental literature is that of Scully in 1980 [11], who described two clinical cases (median age 17.5 years). The first one was a caucasian male 18 years of age, who underwent a dental prophylaxis with an ultrasonic device for presenting chronic marginal gingivitis due to poor oral hygiene. He did not need any other dental treatment afterwards. He was given oral hygiene instructions that later showed a significant improvement of his periodontal health. Meanwhile, the second case was a 17 year-old black male who underwent a dental prophylaxis with an ultrasonic device to treat chronic periodontitis also due to poor oral hygiene. He received oral hygiene instructions as well. He died a year later as a result of pneumonia.

We did not find any other case until 1993. It was Barrett et al [12] who described the case of a 22 yearold female who presented dental pain in several mandibular teeth that also were affected by caries. The patient was epileptic and was treated with clonazepam ( $2 \mathrm{mg}$ twice/day) and carbamazepine (200mg daily). She went under general anesthesia for multiple surgical extractions (26, 34, 36, 45 and 46). A mucoperiosteal flap was raised, and an ostectomy performed due to the extreme bone density and large roots. The patient was sutured and there were no postoperative incidents. She required intravenous administration of factor VIII: C on the morning of the surgery as well as the next morning because she had a variant of von Willebrand disease.

In 2005, Gupta et al [13] presented the case of an 11 year-old male who was in need of orthodontic treatment for having upper front teeth in an extreme buccal position. Two years later, in 2007, Grau Carbó et al [14] reported a case of a 29 year-old female who had temporal teeth, as well as, several ectopic molars extracted. She also received the appropriate periodontal treatment to have dental health. All the procedures were performed under general anesthesia. And seven days later, she was evaluated again to check her oral health, and educate her family about the importance of daily oral hygiene procedures. It was recommended that the patient come to check-ups every 4 months to prevent further disturbances.

Guadagni et al [15] in 2008 described the case of a 3 year-old male who went for a dental check-up due to the neuropsychiatrist's concern that the child was experiencing dental pain, which could be increasing the frequency of the seizures. The child's parents received oral hygiene instructions and dietary advice. The patient was monitored every 2 months to assess the level of hygiene, growth and development of the jaws and tooth eruption. A systemic treatment with fluoride was administered as well as topically. Orthodontic treatment was discarded for lack of patient cooperation, and an absence of chewing and swallowing reflex activity.

Finally, in 2009, Toker et al [16] presented a case of a 10 year-old male that was experiencing dental pain, and whose mother reported having a history of preterm births. The patient had the affected teeth extracted under general anesthesia and there were no complications during the process or in the postoperative period.

Of the studies published to date regarding CdLS, we found 5 articles that included a single case report [12-16] and an article that included a sample of two patients [11]. (Table 2). The mean age of the patients described in this review of 5 clinical cases and a series of 2 cases was almost 16 years (exactly 15.7 years), the age range being between 3 and 29 years. Of the revised dental literarure, only 7 people with this rare syndrome were subjected to an oral examination, being too small a sample to draw firm conclusions as to the degree of oral pathology and the problems that could arise while managing them in the dental clinic.

\section{Discussion}

There are oral manifestations derived mainly from the medication used for the treatment of CdLS [12]. These patients are difficult to evaluate because of a communication problem, the lack of language and the altered pain threshold, which could mask the presence of pain [15].

Just as anxiolytics and anticonvulsants can cause xerostomia, stomatitis, glossitis, erythema multiforme, dysgeusia, etc.., it needs to be considered the possible interactions of these drugs, as in the case of acetylsalicylic acid or erythromycin [12]. Therefore, a detailed medical history, containing all the drugs used by the patient to control the disease is extremely important in order to avoid undesirable side effects.

Thus, we can only distinguish a group of manifestations derived from the specific conditions of CdLS. Orofacial manifestations in patients with CdLS found in the literature are described in Table 2. Their assessment indicates that they are not exclusive of the syndrome, since they can also present in other diseases characterized by the presence of oral patterns, seizures or difficulties with a proper oral hygiene. However, there are some features, such as delayed eruption [11,13,16], anterior open bite [12,15] or gingivitis [11,14], which are more common among patients with CdLS. The pathology associated with poor hygiene, like an early-onset [16] or multiple form of tooth decay [12,14] and periodontal disease [11,14], is closely related to this syndrome due to cognitive difficulties they present.

The unique presence of upper central incisors shaped like those of Hutchinson's suggests a possible link between the symptoms of CdLS and Hutchinson syndrome [16]. A controlled diet, topical fluoride application and periodic check-ups are crucial in the management of these patients $[11,14,15]$ and may limit the use of sedation and general anesthesia for the most extreme cases. In terms of behavior management, it is necessary to consider limitations in the communicative ability of the patient, mental retardation and lack of 
attention. The techniques should always be tailored to each individual case. Some authors have used general anesthesia $[12,14,16]$ due to possible health risks, and the lack of cooperation necessary for proper dental treatment. It can also be exploited to perform other procedures as in the case presented by Grau Carbó et al [14] who made a dilated esophagus with fibrogastroscopy.

\section{Figures And Tables}

Pubmed/MEDLINE search without date restriction until May $10^{\text {th }}, 2016$ :

(Cornelia de Lange syndrome) AND ((dental OR oral) AND (manifestations OR findings))

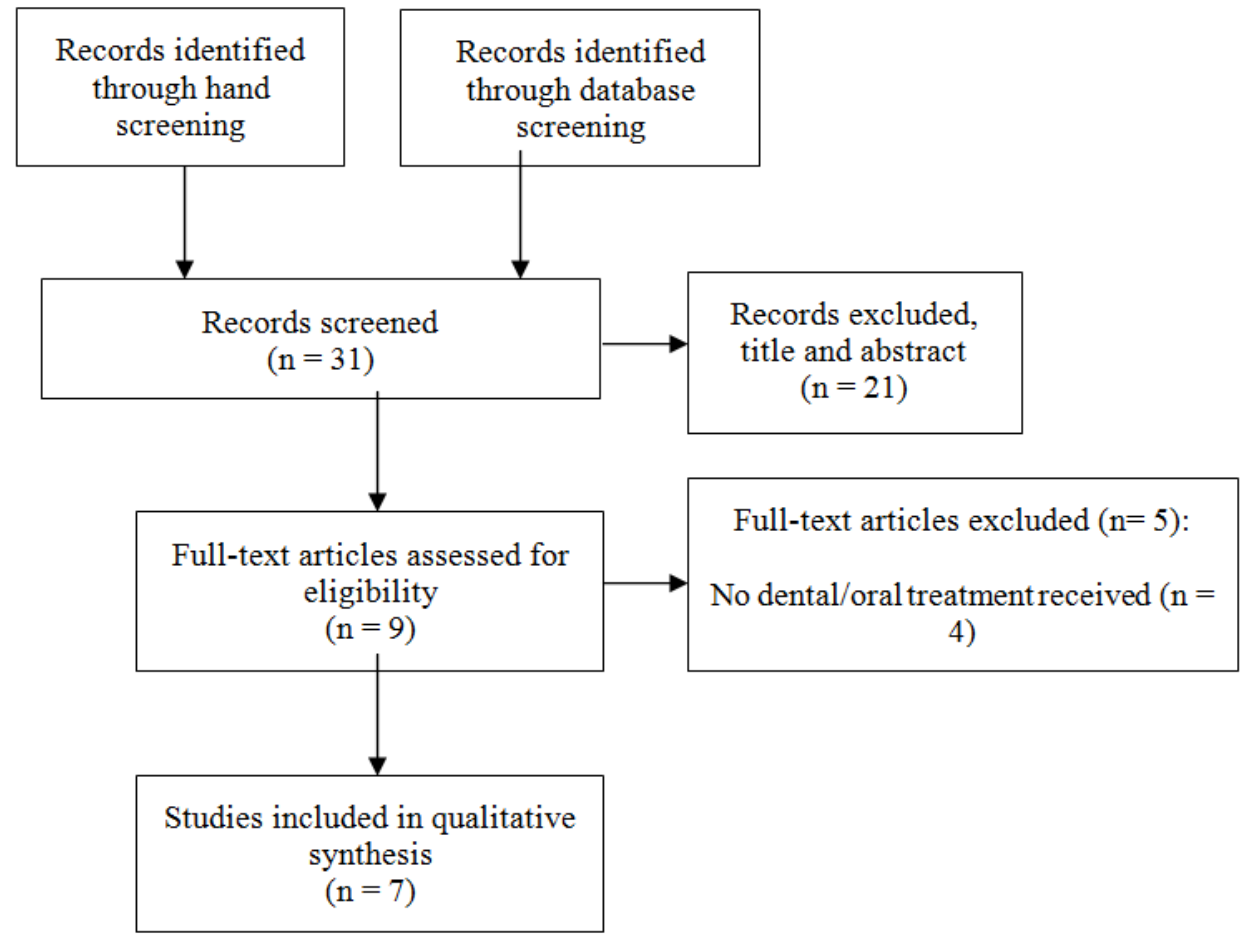

Figure 1. Flow diagram of the literature search.

\begin{tabular}{|c|c|c|c|c|}
\hline $\begin{array}{c}\text { Body } \\
\text { Category }\end{array}$ & No & Main criteria & With & Secondary criteria \\
\hline Facial & & Synophrys (arched, fine eyebrows) & And $\geq 3$ & $\begin{array}{l}\text { Long eyelashes; Short nose, anteverted } \\
\text { nares; Long, prominent philtrum; Broad or } \\
\text { depressed nasal bridge; Small or square } \\
\text { chin; Thin lips, down-turned corners; } \\
\text { High palate; Widely spaced or absent } \\
\text { teeth }\end{array}$ \\
\hline Growth & $\geq 2$ & $\begin{array}{l}\text { Weight below } 5 \text { th centile for age; Height or } \\
\text { length below } 5 \text { th centile for age; OFC below } \\
2 \text { nd centile for age }\end{array}$ & & \\
\hline Development & $\geq 1$ & $\begin{array}{l}\text { Developmental delays or mental retardation; } \\
\text { Learning disabilitites }\end{array}$ & & \\
\hline Behavior & $\geq 2$ & $\begin{array}{l}\text { Attention deficit disorder } \pm \text { hyperactivity; } \\
\text { Obsessive-compulsive characteristics; } \\
\text { Anxiety Constant roaming; Aggression; } \\
\text { Self-injurious behaviour; Extreme shyness } \\
\text { or withdrawal; Autistic-like features }\end{array}$ & & \\
\hline Musculoskeletal & $\begin{array}{l}\text { or } \\
\text { or }\end{array}$ & $\begin{array}{l}\text { Reduction defects with absent forearms } \\
\text { Small hands and/or feet (below } 3^{\text {rd }} \text { centile) or } \\
\text { Oligodactyly } \\
\text { None of these }\end{array}$ & $\begin{array}{l}\text { Only } \\
\text { and } \geq 2 \\
\text { and } \geq 3\end{array}$ & $\begin{array}{l}\text { 5th finger clinodactyly; Abnormal palmar } \\
\text { crease; Radial head dislocation/abnormal } \\
\text { elbow extension; Short 1st } \\
\text { metacarpal/proximally placed thumb } \\
\text { Bunion; Partial } 2,3 \text { syndactyly toes; } \\
\text { Scoliosis; Pectus excavatum; Hip } \\
\text { dislocation or dysplasia }\end{array}$ \\
\hline
\end{tabular}




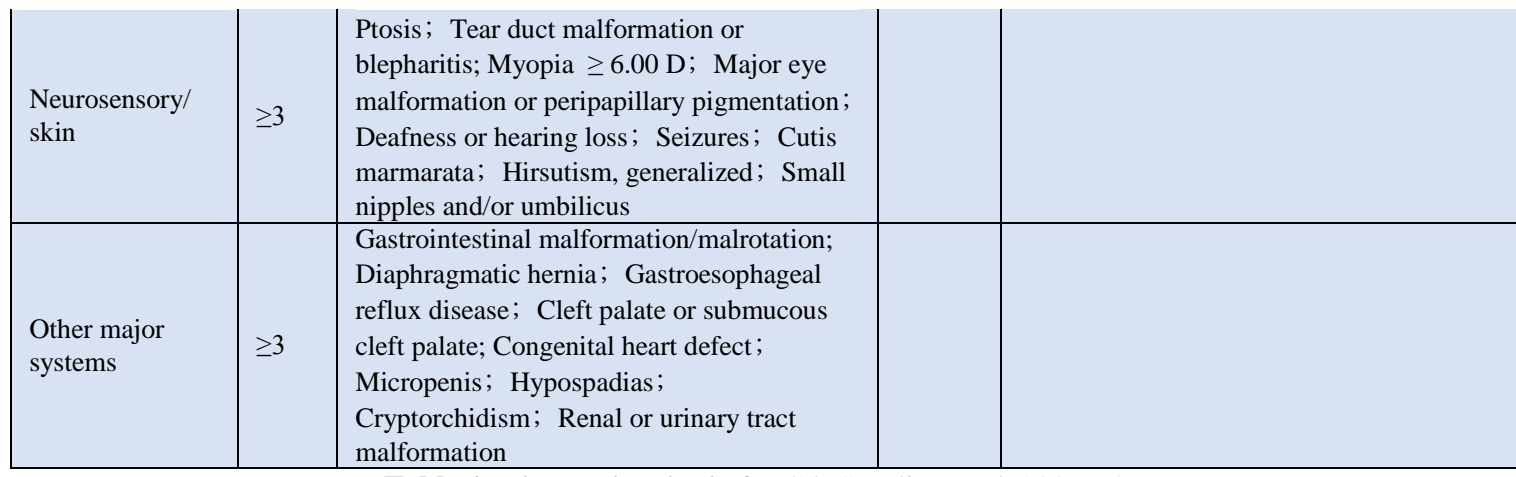

Table 1. Diagnostic criteria for CdLS (Kline et al, 2007) [8].

\begin{tabular}{|c|c|c|c|l|}
\hline Authors & Year & Cases (n) & $\begin{array}{c}\text { Age } \\
\text { (years) }\end{array}$ & \multicolumn{1}{|c|}{ Oral manifestations } \\
\hline Scully [2] & 1980 & 2 & $\begin{array}{l}\text { X=17,5 } \\
(17-18)\end{array}$ & $\begin{array}{l}\text { Dental absences, diastemas, delayed eruption, chronic gingivitis, abnormal } \\
\text { tooth shape, tooth malposition, crowding, periodontal disease and } \\
\text { generalized enamel hypoplasia. }\end{array}$ \\
\hline $\begin{array}{c}\text { Barrett et al } \\
\text { [3] }\end{array}$ & 1993 & 1 & 22 & $\begin{array}{l}\text { Anterior open bite, diastemas, multiple and extensive caries, tooth } \\
\text { impaction, taurodontism in mandibular molars and irregular mandibular } \\
\text { sclerosis. }\end{array}$ \\
\hline $\begin{array}{c}\text { Gupta et al [4] } \\
\text { Grau Carbó et } \\
\text { al [5] }\end{array}$ & 2005 & 1 & 11 & $\begin{array}{l}\text { Persistence of temporary teeth, maxillary prognathism, anterior protrusion } \\
\text { of teeth, Class II div. I maloclussion, delayed root formation and eruption } \\
\text { delays. }\end{array}$ \\
\hline $\begin{array}{c}\text { Guadagni et al } \\
\text { [6] }\end{array}$ & 2008 & 1 & 29 & $\begin{array}{l}\text { Multiple caries, moderate periodontal disease, persistence of temporary } \\
\text { teeth and ectopically erupted molars }\end{array}$ \\
\hline Toker et al [7] & 2009 & 1 & 10 & $\begin{array}{l}\text { Micrognatism, hypotonic facial and masticatory muscles, drooling, severe } \\
\text { anterior open bite, arched palate, class III maloclussion, agenesis, } \\
\text { macrodontia, enamel hypomineralization, short upper lip, and } \\
\text { ankyloglossia, tongue protrusion and jaw muscle contraction. }\end{array}$ \\
\hline
\end{tabular}

Table 2. Oral manifestations of Cornelia de Lange syndrome found in the dental literature.

\section{Conclusion}

In conclusion, this review shows that oral habits should be strongly considered in these patients because it may lead to malocclusion and anterior open bite or an arched palate. However, the most representative clinical feature of CdLS is a delayed eruption, which may be the cause of other events such as the presence of diastemas and / or malocclusions that are difficult to treat without early diagnosis, due to the lack of collaboration of these patients.

There are no acknowledgements.

\section{Acknowledgements}

\section{References}

[1] Noor N, Kazmi Z, Mehnaz A. Cornelia de Lange syndrome. J Coll Physicians Surg Pak. 2012; 22(6): $412-413$

[2] Ireland M, Donnai D, Burn J. Brachmann-de Lange syndrome. Delineation of the clinical phenotype. Am J Med Genet. 1993; 47(7): 959-964.

[3] Dubois-Dalcq M. Typus Amstelodamensis (Cornelia De Lange 1933). 1st Case in Belgium. Acta Neurol Belg. 1964; 64: $370-384$.

[4] Meinecke P, Hayek H. Brief historical note on the Brachmann-de Lange syndrome: a patient closely resembling the case described by Brachmann in 1916. Am J Med Genet. 1990; 35(3): 449-450.

[5] Barisic I, Nelen V, Gillerot I, De Vignan C, Doray B, Francannet C, et al. Descriptive epidemiology of Cornelia de Lange syndrome in Europe. American Journal of Medical Genetics, Part A. 2008; 146(1): 51-59.

[6] Wierzba J, Gil-Rodriguez MC, Polucha A, Puisac B, Arnedo M, Teresa-Rodrigo ME, et al. Cornelia de Lange syndrome with NIPBL mutation and mosaic Turner syndrome in the same individual. BMC Med Genet. 2012; 13:43.

[7] Krantz ID, McCallum J, DeScipio C, Kaur M, Gillis LA, Yaeger D, et al. Cornelia de Lange syndrome is caused by mutations in NIPBL, the human homolog of Drosophila melanogaster Nipped-B. Nat Genet. 2004; 36(6): 631-635.

[8] Kline AD, Krantz ID, Sommer A, Kliewer M, Jackson LG, FitzPatrick DR, et al. Cornelia de Lange syndrome: clinical review, diagnostic and scoring systems, and anticipatory guidance. Am J Med Genet A. 2007; 143A(12): 1287-1296.

[9] Murray JE, Walayat M, Gillett P, Sharkey FH, Rajan D, Carter NP, et al. An atypical facial appearance and growth pattern in a child with Cornelia de Lange Syndrome: an intragenic deletion predicting loss of the N-terminal region of NIPBL. Clin Dysmorphol. 2012; 21(1): 22-23.

[10] Verrotti A, Agostinelli S, Prezioso G, Coppola G, Capovilla G, Romeo A, et al. Epilepsy in patients with Cornelia de Lange syndrome: a clinical series. Seizure. 2013; 22(5): 356-359.

[11] Scully C. The de Lange syndrome: report of two cases. J Oral Med. 1980; 35(2): 32-34.

[12] Barrett AW, Griffiths MJ, Scully C. The de Lange syndrome in association with a bleeding tendency: oral surgical implications. Int 
J Oral Maxillofac Surg. 1993; 22(3): 171-172.

[13] Gupta D, Goyal S. Cornelia de-Lange syndrome. J Indian Soc Pedod Prev Dent. 2005; 23(1): 38-41.

[14] Grau Carbo J, Lopez Jimenez J, Gimenez Prats MJ, Sanchez Molins M. Cornelia de Lange syndrome: a case report. Med Oral Patol Oral Cir Bucal. 2007; 12(6): E445-8.

[15] Guadagni MG, Cetrullo N, Piana G. Cornelia de Lange syndrome: description of the orofacial features and case report. Eur J Paediatr Dent. 2008; 9(4): 9-13.

[16] Toker AS, Ay S, Yeler H, Sezgin I. Dental findings in Cornelia de Lange syndrome. Yonsei Med J. 2009; 50(2): $289-292$. 